\title{
Chronic CaMKII inhibition blunts the cardiac contractile response to exercise training
}

\author{
Guri Kaurstad • Marcia N. Alves • Ole J. Kemi • \\ Natale Rolim • Morten A. Høydal · Helene Wisløff • \\ Tomas O. Stølen • Ulrik Wisløff
}

Received: 23 November 2010/Accepted: 30 April 2011/Published online: 26 May 2011

(C) The Author(s) 2011. This article is published with open access at Springerlink.com

\begin{abstract}
Activation of the multifunctional $\mathrm{Ca}^{2+} /$ calmodulin-dependent protein kinase II (CaMKII) plays a critical role modulating cardiac function in both health and disease. Here, we determined the effect of chronic CaMKII inhibition during an exercise training program in healthy mice. CaMKII was inhibited by KN-93 injections. Mice were randomized to the following groups: sham sedentary, sham exercise, KN-93 sedentary, and KN-93 exercise. Cardiorespiratory function was evaluated by ergospirometry during treadmill running, echocardiography, and cardiomyocyte fractional shortening and calcium handling.
\end{abstract}

Communicated by Keith Phillip George.

G. Kaurstad - M. N. Alves · N. Rolim - M. A. Høydal ·

T. O. Stølen · U. Wisløff

K.G. Jebsen Center of Exercise in Medicine,

Norwegian University of Science and Technology (NTNU),

Trondheim, Norway

G. Kaurstad - M. N. Alves - N. Rolim - M. A. Høydal ·

T. O. Stølen · U. Wisløff $(\bowtie)$

Department of Circulation and Medical Imaging,

Norwegian University of Science and Technology (NTNU),

Olav Kyrresgate 9, Postboks 8905, 7491 Trondheim, Norway

e-mail: ulrik.wisloff@ntnu.no

\section{O. J. Kemi}

Institute of Cardiovascular and Medical Sciences,

University of Glasgow, Glasgow, UK

H. Wisløff

Department of Pathology, National Veterinary Institute,

Oslo, Norway

U. Wisløff

Centre for Sports and Physical Activity Research,

Norwegian University of Science and Technology (NTNU),

Trondheim, Norway
The results revealed that $\mathrm{KN}-93$ alone had no effect on exercise capacity or fractional shortening. In sham animals, exercise training increased maximal oxygen uptake by $8 \%$ $(p<0.05)$ compared to a $22 \%(p<0.05)$ increase after exercise in $\mathrm{KN}-93$ treated mice (group difference $p<0.01$ ). In contrast, in vivo fractional shortening evaluated by echocardiography improved after exercise in sham animals only: from 25 to $32 \%(p<0.02)$. In inactive mice, $\mathrm{KN}-93$ reduced rates of diastolic cardiomyocyte relengthening (by $25 \%, p<0.05$ ) as well as $\mathrm{Ca}^{2+}$ transient decay (by $16 \%, p<0.05$ ), whereas no such effect was observed after exercise training. KN-93 blunted exercise training response on cardiomyocyte fractional shortening (63\% sham vs. $18 \% \mathrm{KN}-93 ; p<0.01$ and $p<0.05$, respectively). These effects could not be solely explained by the $\mathrm{Ca}^{2+}$ transient amplitude, as $\mathrm{KN}-93$ reduced it by $20 \%(p<0.05)$ and response to exercise training was equal (64\% sham and $47 \% \mathrm{KN}-93$; both $p<0.01$ ). We concluded that chronic CaMKII inhibition increased time to $50 \%$ re-lengthening which were recovered by exercise training, but paradoxically led to a greater increase in maximal oxygen uptake compared to sham mice. Thus, the effect of chronic CaMKII inhibition is multifaceted and of a complex nature.

Keywords Aerobic interval training $\cdot \mathrm{KN}-93 \cdot$ Exercise training and cardiac function $\cdot$ CaMKII inhibition in healthy mice

\section{Introduction}

The ubiquitous and multifunctional $\mathrm{Ca}^{2+} /$ calmodulindependent protein kinase II (CaMKII) regulates a number of intracellular processes related to cellular contractility 
and nuclear gene expression, thereby controlling the pump function and growth of the heart. Some of the specific targets include the L-type $\mathrm{Ca}^{2+}$ channel, the sarcoplasmic reticulum (SR) $\mathrm{Ca}^{2+}$ release channel (ryanodine receptor 2, RyR2), phospholamban (PLB), $\mathrm{Na}^{+}$and $\mathrm{K}^{+}$channels making CaMKII a prominent regulator of excitation-contraction coupling (Couchonnal and Anderson 2008; Hashambhoy et al. 2010; Maier et al. 2007; Maier and Bers 2002). Furthermore, CaMKII can regulate nuclear gene expression on class II histone deacetylase (HDAC), which increases myocyte-enhanced factor 2 (Mef2)-regulated transcription (Erickson and Anderson 2008; Maier and Bers 2002, 2007; Maier et al. 2007; Sag et al. 2009). However, the functional consequences of CaMKII activation are still unclear, since heart failure is associated with increased CaMKII (Anderson 2005; Anderson et al. 1998; Couchonnal and Anderson 2008; Khoo et al. 2006; VilaPetroff et al. 2007; Zhang et al. 2005); in fact, CaMKII may constitute a molecular switch between cardiac hypertrophy and failure (Zhang et al. 2005), and CaMKII activation may also precede arrhythmic events and contractile dysfunction, mainly because of its effect on the RyR2 (Anderson 2005; Ling et al. 2009; van Oort et al. 2010). On the other hand, improved contractile function after aerobic interval exercise training also associates with activated CaMKII, but in this scenario, the main effect is on the SR $\mathrm{Ca}^{2+}$ uptake due to phosphorylation of PLB. Interestingly, in mice with type-2 diabetes with chronically increased cardiac CaMKII and reduced cardiomyocyte contractile function and $\mathrm{Ca}^{2+}$ handling, aerobic interval exercise training resulted in reduced levels of CaMKII and improved cardiomyocyte contractile function and $\mathrm{Ca}^{2+}$ handling (Stolen et al. 2009). Recent studies have shown that CaMKII negatively regulates calcineurin activity (Khoo et al. 2006; MacDonnell et al. 2009), which in turn regulates mitochondrial respiration, and further complicates the role of CaMKII (Jiang et al. 2010; Wang et al. 2011).

The exact role of CaMKII activation in the heart remains unclear, as it associates with dysfunction, failure, and propensity for arrhythmias, but also with increased function under different circumstances such as exercise training. Based on the potential clinical value of chronic CaMKII inhibition (Khoo et al. 2006; Sag et al. 2009; Zhang et al. 2005) and the beneficial effect of exercise training on delaying cardiac dysfunction and correcting function after onset of heart disease (Stolen et al. 2009; Wisloff et al. 2002, 2007; Adams et al. 2005; Erbs et al. 2010; Mezzani et al. 2008; Hambrecht et al. 2000; Anderson et al. 1998; Kemi et al. 2007; Zhang et al. 2005) two scenarios that may mutually oppose each other, determining the effect of chronic CaMKII inhibition on the response to exercise training would be of considerable interest. Therefore, we aimed to study the effect of chronic CaMKII inhibition during the course of an exercise training program in healthy mice. We hypothesized that chronic CaMKII inhibition would abolish the normal exercise training response in the hearts.

\section{Materials and methods}

Mice and CaMKII inhibition

Eighteen female C57 BL/6J mice (Møllegaard Breeding Center, Lille Skensved, Denmark) 18-20 g, 8 weeks of age at inclusion were randomized into four groups: (1) sham control sedentary, (2) sham control exercise training, (3) KN-93 sedentary, and (4) KN-93 exercise training. KN-93 (2-[N-(2-hydroxyethyl)- $N$-(4 methoxybenzenesulfonyl)] amino- $N$-(4-chlorocinnamyl)- $N$-methylbenzylamine; AlexisBiochemical, Enzo Life Science, PA, USA) diluted in dimethyl sulfoxide (DMSO, Sigma-Aldrich, St. Louis, MO, USA, $2 \mathrm{mg} \mathrm{KN}-93 / 1 \mathrm{~mL}$ DMSO, $10 \mu \mathrm{mol} / \mathrm{kg}$ (Zhang et al. 2005)) was intraperitoneally injected daily after the exercise training session (for those that exercise trained), throughout the experimental period. In a previous study, Zhang et al. (2005) observed dose-dependent CaMKII inhibition by KN-93, in which daily injections of $10 \mu \mathrm{mol} /$ $\mathrm{kg} \mathrm{KN}-93$ produced similar effect on left ventricular contraction measurements as the genetically CaMKII-inhibited AC3:I mice (Zhang et al. 2005; Khoo et al. 2006). Sham control mice received similar amounts of DMSO daily. The Norwegian council for Animal Research approved the study, which was in accordance with the Guide for the Care and Use of Laboratory Animals (National Institutes of Health Publications No. 85-23, revised 1996).

\section{Exercise training}

Exercise training was performed as aerobic interval training for 6 weeks, 5 days/week, on an inclined $\left(25^{\circ}\right)$ treadmill, each session starting with a 10-min warm-up at $50-60 \%$ of maximal oxygen uptake $\left(V \mathrm{O}_{2 \max }\right)$, whereupon exercise then alternated between 4- and 2-min intervals at 85-90 and 50-60\% of $V_{2}$ max, respectively for $60 \mathrm{~min}$. $V \mathrm{O}_{2 \max }$ was assessed during a treadmill running test to exhaustion in a metabolic chamber. After a warm-up period of about $10 \mathrm{~min}$, treadmill band velocity was increased by $0.03 \mathrm{~m} / \mathrm{s}$ for every second minute until mice were not able to maintain the treadmill velocity (Hoydal et al. 2007; Kemi et al. 2002). To maintain the exercise intensity throughout the experimental period, $V \mathrm{O}_{2 \max }$ was tested at the beginning of each week in addition to pre- and posttests. This exercise protocol has previously been proven efficient for inducing exercise and cardiovascular 
adaptations in both the clinical and experimental studies (Tjonna et al. 2008; Hoydal et al. 2007; Kemi et al. 2002, 2005; Wisloff et al. 2001; Stolen et al. 2009).

\section{Echocardiography}

High-resolution echocardiography (Vevo 770, VisualSonics, Toronto, Canada) using a single-element mechanical transducer with a center frequency of $30 \mathrm{MHz}$ was performed on self-breathing mice exposed to a mixture of $2 \%$ isoflurane and $98 \%$ oxygen. A two-dimensional long-axis view was used to visualize both ventricles, the ascending aorta, and the right ventricular outflow tract by placing the ultrasound transducer on the left parasternal position, whereas a short-axis view was used to visualize systolic and diastolic movement of both ventricles by placing the transducer horizontally above the heart. Left ventricular enddiastolic diameter (LVEDD), left ventricular end-systolic diameter (LVESD), interventricular septum (IVST) and posterior wall thickness (PWT) were recorded with M-mode echocardiography, which allowed calculation of the fractional shortening $(\%=[($ LVEDD - LVESD $) /$ LVEDD $] \times$ [100]) as an index of systolic left ventricular function. The following equation was used to calculate LV $\operatorname{mass}(\mathrm{mg})=\left[(\mathrm{LVEDD}+\mathrm{IVST}+\mathrm{PWT})^{3}-\mathrm{LVEDD}^{3}\right] \times$ 1.055 , where $1.055\left(\mathrm{mg} / \mathrm{mm}^{3}\right)$ is the density of myocardium. IVST and PWT were measured at end diastole.

Cardiomyocyte isolation, contractile function, $\mathrm{Ca}^{2+}$ measurements and cell size

Left ventricular cardiomyocytes were isolated as previously described using a Hepes-based solution (Mitra and Morad 1981; Guatimosim et al. 2001). Exercised hearts were excised $24 \mathrm{~h}$ after the last exercise session. A mixture of 3-4\% isoflurane and 96-97\% oxygen were used to anesthetize the mice, whereupon the heart was heparinized and removed. Until it was connected to the aortic cannula on a standard Langendorff retrograde perfusion system, the hearts were kept on ice cold Hepes solution. The hearts were cleaned with a Hepes solution containing EGTA (Sigma-Aldrich Corp., Missouri, USA) before the perfusion was switched to Hepes solution with collagenase (Worthington, Lakewood, USA), and perfusion was continued for approximately $10 \mathrm{~min}(3.5 \mathrm{ml} / \mathrm{min})$. After the hearts were taken down, left ventricles were carefully cut off and gently shaken for 2 min before the non-digested tissue was filtered out (nylon mesh, $250 \mu \mathrm{m}$ ). Further, cells were stepwise exposed to increasing $\mathrm{Ca}^{2+}$ levels (initially $0.05 \mathrm{mM})$. The isolated cells were centrifuged $(30 \mathrm{~s}$, $600 \mathrm{rpm}$ ) before solution was switched to $1.2 \mathrm{mM}$ Hepesbased solution. Fura-2/AM-loaded $(2 \mu \mathrm{mol} / \mathrm{l}$, Molecular Probes, Eugene, OR, USA) cardiomyocytes were field stimulated by bipolar electrical pulse at $1 \mathrm{~Hz}$, on an inverted epifluorescence microscope (Nikon TE-2000E, Tokyo, Japan), whereupon cell shortening was recorded by video-based myocyte sarcomere spacing $\left(\operatorname{SarcLen}^{\mathrm{TM}}\right.$, IonOptix, Milton, MA, USA) and intracellular $\mathrm{Ca}^{2+}$ concentration was measured by fluorescence after excitation by alternating 340 and $380 \mathrm{~nm}$ wavelengths ( $F^{340 / 380}$ ratio) (Optoscan, Cairn Research, Kent, UK). Cells with a clear visual intracellular structure that were able to follow stimulation frequency were included for the experiment. The total number of cardiomyocytes included for all analysis in the different groups was: sham sedentary 8 , sham exercise 20, KN-93 sedentary 5, and in KN-93 exercise 9. During the stimulation protocol, cells were kept in $1.2 \mathrm{mM} \mathrm{Ca}^{2+}$ HEPES-based solution at $37^{\circ} \mathrm{C}$. Cell size was measured with Nikon Eclipse E400 Microscope with a DSFil camera (Nikon NIS-Elements Basic Research Version 3.00 software, Nikon Instruments Inc., Melville, NY, USA). Cardiomyocyte size was measured on $80-120$ cardiomyocytes per group.

\section{Statistics}

A one-way ANOVA with LSD post hoc test was used to detect significant differences between groups. For withingroup differences from pre- to post-test, a paired sample $T$ test was used. Statistical significance level was set to $p<0.05$.

\section{Results}

$V \mathrm{O}_{2 \max }$ and exercise capacity

In sedentary mice, daily intraperitoneal injections of the CaMKII-selective inhibitor KN-93 did not affect $V \mathrm{O}_{2 \max }$, running speed at $V \mathrm{O}_{2 \max }$, or body mass (Fig. 1). However, while chronic CaMKII inhibition had no effect in sedentary mice, it did affect the response to exercise training. Whereas exercise training increased $V \mathrm{O}_{2 \max }$ by $8 \%(p<0.05)$ in sham, the effect was $22 \%(p<0.01)$ in $\mathrm{KN}-93$ mice after the exercise training period (magnitude of response difference $p<0.01$, Fig. 1a). KN-93 tended to suppress the growth in body mass (Fig. 1c), which made it necessary to normalize $V \mathrm{O}_{2 \max }$ according to correct scaling procedures, which involves the correct normalization of a physiological variable (here $V \mathrm{O}_{2 \max }$ ) to a body dimension (here body mass). It is well established that cardiorespiratory capacity in lighter individuals will be overestimated compared to heavier ones when $V \mathrm{O}_{2 \max }$ is expressed in direct relation to body mass (i.e., $\mathrm{ml} / \mathrm{kg} / \mathrm{min}$ ) and that $V \mathrm{O}_{2 \max }$ should be expressed with body mass raised to the power of 0.75 (i.e., $\mathrm{ml} / \mathrm{kg}^{0.75} / \mathrm{min}$ ) when comparing individuals that differ in 
Fig. 1 Values of $V \mathrm{O}_{2 \max }(\mathbf{a})$, maximal aerobic running speed (b), and body mass (c), before and after the exercise training intervention (pre- and posttests), presented as mean values $\pm \mathrm{SD} .{ }^{*} p<0.05$ versus sedentary; $* * p<0.01$ versus sedentary; ${ }^{\# \#} p<0.01$ versus sham exercise; ${ }^{\S} p<0.05$ versus pre-test a

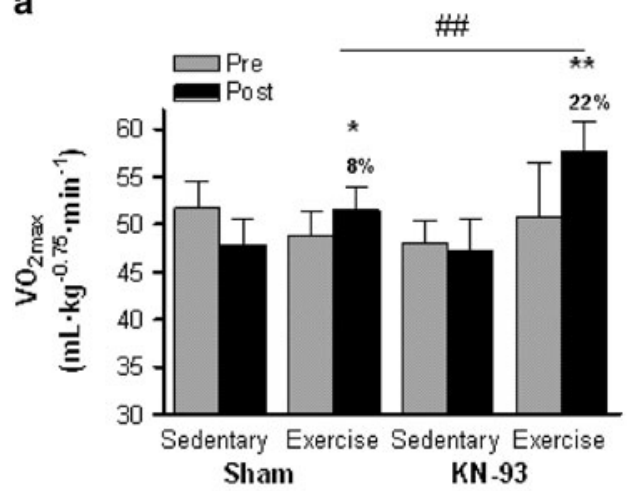

C

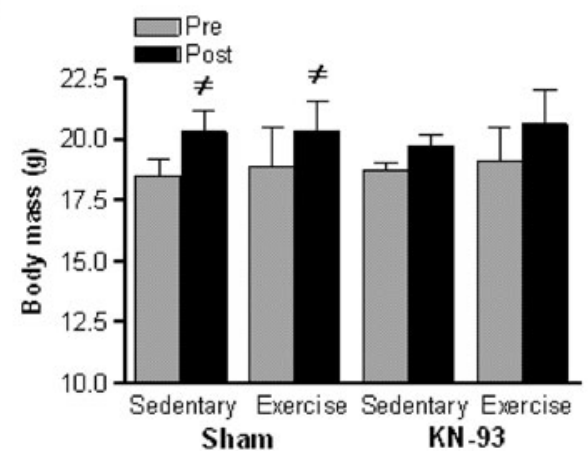

b

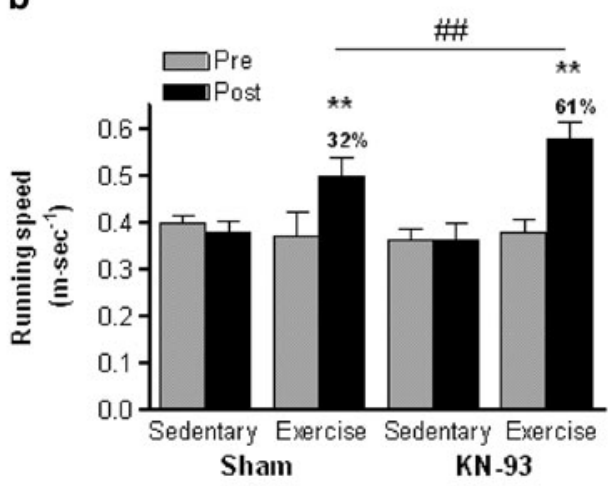

body mass (Taylor et al. 1981). Hence, $V \mathrm{O}_{2 \max }$ was divided by body mass raised to the power of 0.75 as an exponent in the present study in order not to overestimate the effect of $\mathrm{KN}-93$ on $V \mathrm{O}_{2 \max }$. In line with a larger increase in $V \mathrm{O}_{2 \max }$ after exercise training in $\mathrm{KN}-93$ mice, we observed that running speed at $V \mathrm{O}_{2 \max }$ also increased twice as much compared to that observed in sham mice $32 \%(p<0.01)$, and $61 \%(p<0.01)$ in KN-93 mice.

Cardiac remodeling

KN-93 injections did not significantly change LVEDD, LVESD, PWT, or IVST (Table 1). However, there was a trend for decreased LV mass, and LVEDD in sedentary KN-93 treated mice compared to sham sedentary.

Also, CaMKII inhibition by KN-93 injections did not affect cardiomyocyte size in sedentary mice, measured as cell length and width in isolated cardiomyocytes, but it did blunt the exercise training-induced hypertrophy of the cardiomyocytes. Exercise-induced cardiomyocyte hypertrophy was observed in both sham and KN-93 mice, but the effect was larger in sham mice. Exercise training increased cardiomyocyte length and width by $13 \%(p<0.05)$ and $30 \%(p<0.05)$ in sham mice, and by $8 \%(p<0.05)$ and $14 \%(p<0.05)$ in $\mathrm{KN}-93$ mice, respectively (group differences $p<0.05$, Fig. 2a, b). Thus, the cardiomyocyte hypertrophy response to exercise in $\mathrm{KN}-93$ mice was approximately half of that in sham mice.
Table 1 Two-dimensional echocardiography measurements

\begin{tabular}{|c|c|c|c|c|}
\hline & \multicolumn{2}{|l|}{ Sham } & \multicolumn{2}{|l|}{ KN-93 } \\
\hline & Sedentary & Exercise & Sedentary & Exercise \\
\hline$n$ & 6 & 4 & 4 & 4 \\
\hline \multicolumn{5}{|c|}{ Echocardiography } \\
\hline $\begin{array}{l}\text { HR } \\
\text { (beats/min) }\end{array}$ & $441 \pm 21.3$ & $450 \pm 36.2$ & $478 \pm 18.0$ & $447 \pm 36.4$ \\
\hline $\begin{array}{l}\text { SV } \\
\qquad(\mu 1 / \min )\end{array}$ & $23.7 \pm 4.0$ & $25.2 \pm 1.4$ & $20.2 \pm 5.7$ & $25.4 \pm 6.0$ \\
\hline $\begin{array}{l}\mathrm{CO} \\
(\mathrm{ml} / \mathrm{min})\end{array}$ & $10.4 \pm 1.8$ & $11.3 \pm 1.4$ & $9.7 \pm 2.7$ & $11.3 \pm 2.3$ \\
\hline $\begin{array}{l}\text { LVEDD } \\
(\mathrm{mm})\end{array}$ & $3.7 \pm 0.2$ & $3.7 \pm 0.2$ & $3.5 \pm 0.3$ & $3.8 \pm 0.2$ \\
\hline $\begin{array}{l}\text { LVESD } \\
(\mathrm{mm})\end{array}$ & $2.8 \pm 0.3$ & $2.5 \pm 0.3$ & $2.6 \pm 0.2$ & $2.7 \pm 0.1$ \\
\hline $\begin{array}{l}\text { LV mass } \\
(\mathrm{mg})\end{array}$ & $96 \pm 11.7$ & $94 \pm 8.7$ & $85 \pm 23.5$ & $99 \pm 23.0$ \\
\hline FS (\%) & $25 \pm 4.5$ & $32 \pm 5.2 *$ & $28 \pm 3.2$ & $30 \pm 1.6$ \\
\hline $\begin{array}{l}\text { PWT } \\
(\mathrm{mm})\end{array}$ & $0.69 \pm 0.07$ & $0.7 \pm 0.09$ & $0.75 \pm 0.09$ & $0.7 \pm 0.11$ \\
\hline $\begin{array}{l}\text { IVST } \\
(\mathrm{mm})\end{array}$ & $0.74 \pm 0.06$ & $0.66 \pm 0.14$ & $0.7 \pm 0.12$ & $0.68 \pm 0.06$ \\
\hline
\end{tabular}

Data are presented as mean values $\pm \mathrm{SD}$

$H R$ heart rate, $S V$ stroke volume, $C O$ cardiac output, $L V E D D$ left ventricular end-diastolic dimension, LVESD left ventricular end-systolic dimension, FS fractional shortening, PWT posterior wall thickness, IVST intraventricular septal thickness

$* p<0.05$ versus sedentary 

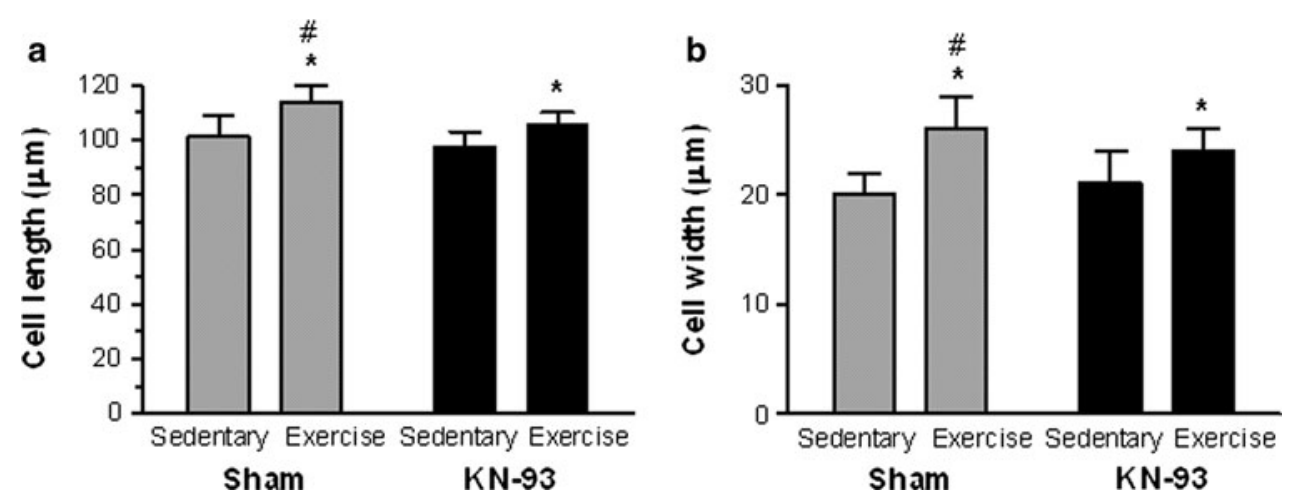

Fig. 2 Isolated cardiomyocyte dimension; cell length (a), and cell width (b), presented as mean values \pm SD. ${ }^{*} p<0.05$ versus sedentary; ${ }^{\#} p<0.05$ versus $\mathrm{KN}-93$ exercise

Cardiac contractile function

According to the measurements of in vivo cardiac function with echocardiography, KN-93 injections did not significantly affect heart rate, stroke volume (SV), cardiac output or fractional shortening (Table 1; Fig. 3). In contrast to $V \mathrm{O}_{2 \max }$ and exercise capacity, left ventricular fractional shortening improved from 25 to $32 \%$ after exercise training in sham mice ( $28 \%$ training response, $p<0.02)$. Cardiac contractile function is largely dependent on $\mathrm{Ca}^{2+}$ handling properties. Systolic $\mathrm{Ca}^{2+}$ and diastolic $\mathrm{Ca}^{2+}$ level were significantly increased by KN-93 injections (Fig. 4a, b, $p<0.01)$. Only sham exercise increased systolic $\mathrm{Ca}^{2+}$ levels (Fig. 4a, $p<0.05$ ), and decreased diastolic $\mathrm{Ca}^{2+}$ level (Fig. $4 \mathrm{~b}, p<0.01$ ).

Chronic CaMKII inhibition by KN-93 injections induced a reduction of the cardiomyocyte ability to relengthen (25\% increased time to 50\% re-lengthening; Fig. $4 c, p<0.05)$ after twitch contractions. This was at least partly explained by the $16 \%$ increase in the $\mathrm{Ca}^{2+}$ transient decay time (Fig. $4 \mathrm{~d}, p<0.05$ ). Exercise training normalized cardiomyocyte re-lengthening and $\mathrm{Ca}^{2+}$ tran-

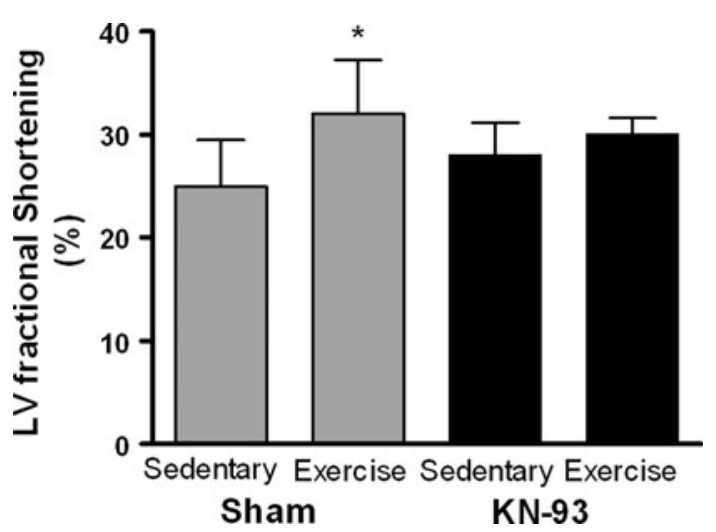

Fig. 3 In vivo LV fractional shortening, presented as mean values \pm SD. ${ }^{*} p<0.05$ versus sedentary sient decay times to levels comparable to sedentary sham mice, and the response to exercise training was not different between sham and $\mathrm{KN}-93$ mice. In particular, exercise training decreased the re-lengthening time by $12 \%$ $(p<0.05)$ and $16 \%(p<0.05)$ in sham and KN-93 mice, respectively, which was linked to comparable exercise training-induced changes in the $\mathrm{Ca}^{2+}$ transient decay times (Fig. 4c, d).

In contrast to the above, the observed effects of KN-93 and exercise training on cardiomyocyte fractional shortening (amplitude of the contraction) and the associated $\mathrm{Ca}^{2+}$ transient amplitude showed a more complex nature. First, KN-93 reduced the $\mathrm{Ca}^{2+}$ transient amplitude by $20 \%$ (Fig. $4 \mathrm{e}, p<0.05$ ), but this did not translate into a comparable reduction in the fractional shortening, as no effect was observed. Second, fractional shortening improved by exercise training, but the response was blunted in $\mathrm{KN}-93$ mice compared to sham mice. Exercise training in sham mice increased fractional shortening by $63 \%(p<0.01)$, but only by $18 \%(p<0.05)$ in $\mathrm{KN}-93$ mice (magnitude of response difference $p<0.05$, Fig. 4f). This could not be solely explained by changes to the $\mathrm{Ca}^{2+}$ transient amplitude, as the exercise training response did not differ between sham and KN-93 mice; sham increased by $64 \%$ $(p<0.01)$, and $\mathrm{KN}-93$ by $47 \%(p<0.01)$ in response to exercise training (Fig. 4e). Table 2 provides an overview of the effects of CaMKII inhibition on whole-body and cardiac, and cardiomyocyte exercise training response.

\section{Discussion}

Given that (1) experimental trials (Anderson 2005; Zhang et al. 2005; Grimm and Brown 2010) have raised the possibility that systemic CaMKII inhibition may be a viable and effective strategy for the treatment of heart disease, and (2) exercise training in both experimental (Rose et al. 2007; Wisloff et al. 2002; Stolen et al. 2009) and clinical 
Fig. 4 Cardiomyocyte systolic $\mathrm{Ca}^{2+}$ level (a), diastolic $\mathrm{Ca}^{2+}$ level (b), time to $50 \%$ diastolic re-lengthening $(\mathbf{c}), \mathrm{Ca}^{2+}$ transient decay time (d), intracellular $\mathrm{Ca}^{2+}$ transient amplitude (e), and fractional shortening (f), presented as mean values \pm SD. $* p<0.05$ versus sedentary; $* * p<0.01$ versus sedentary; ${ }^{*} p<0.05$ versus $\mathrm{KN}-93$ exercise; ${ }^{\# \#} p<0.01$ versus $\mathrm{KN}-93$ exercise; ${ }^{\S} p<0.05$ versus sham sedentary; ${ }^{\S} p<0.01$ versus sham sedentary
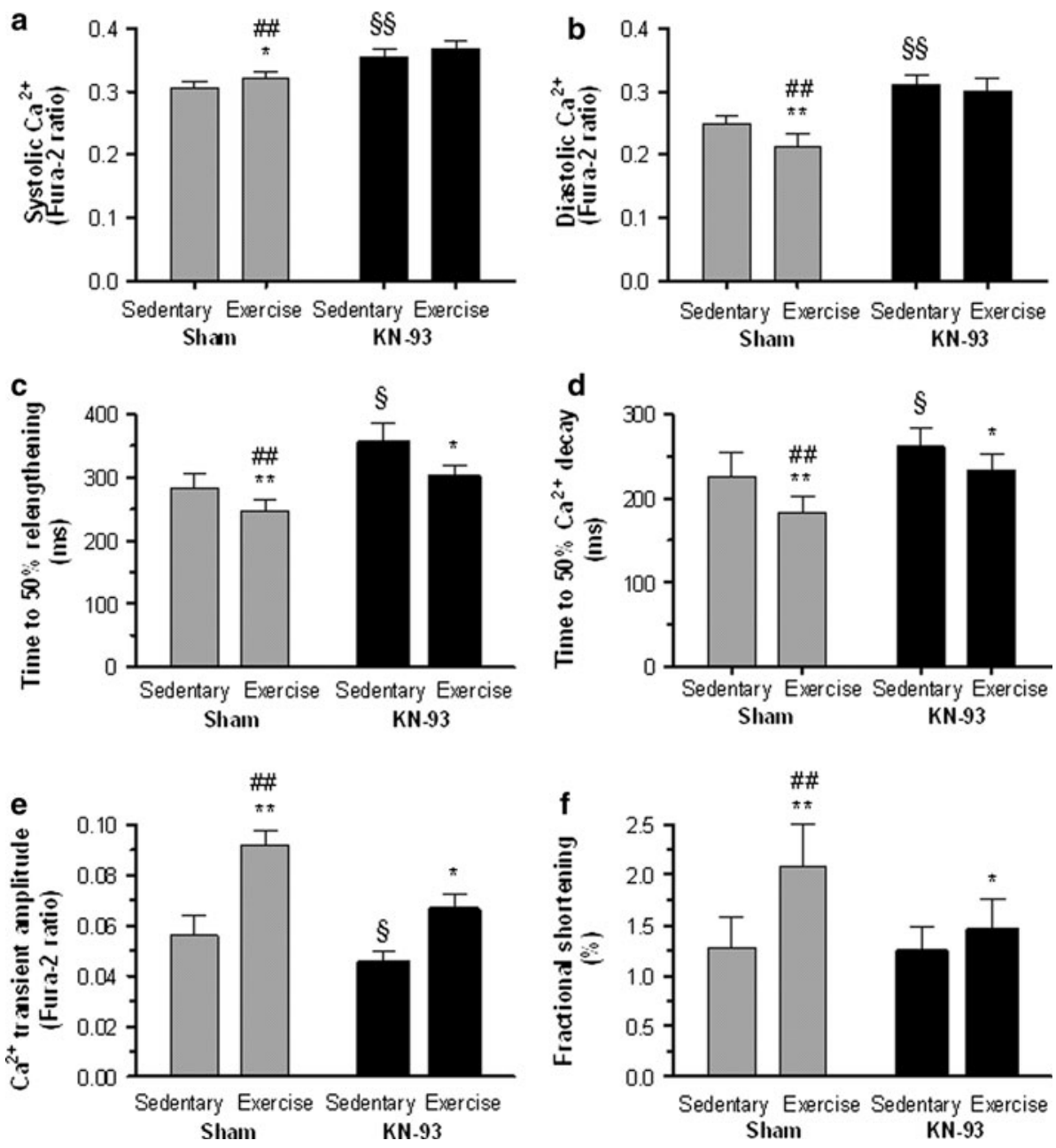

Table 2 Comparison of effects of CaMKII inhibition on exercise training response

\begin{tabular}{|c|c|c|}
\hline Variable & $\begin{array}{l}\text { Sham } \\
\text { exercise }\end{array}$ & $\begin{array}{l}\mathrm{KN}-93 \\
\text { exercise }\end{array}$ \\
\hline \multicolumn{3}{|l|}{ Aerobic exercise capacity } \\
\hline$V \mathrm{O}_{2 \max }$ & $\uparrow$ & $\uparrow \uparrow$ \\
\hline \multicolumn{3}{|l|}{ Echocardiography } \\
\hline LV fractional shortening & $\uparrow$ & $\leftrightarrow$ \\
\hline \multicolumn{3}{|l|}{ Cardiomyocyte $\mathrm{Ca}^{2+}$ handling } \\
\hline Systolic $\mathrm{Ca}^{2+}$ & $\uparrow$ & $\uparrow$ \\
\hline Diastolic $\mathrm{Ca}^{2+}$ & $\downarrow$ & $\leftrightarrow$ \\
\hline Fractional shortening & $\uparrow \uparrow$ & $\uparrow$ \\
\hline $\mathrm{Ca}^{2+}$ transient amplitude & $\uparrow$ & $\uparrow$ \\
\hline Time to $50 \%$ re-lengthening & $\downarrow$ & $\downarrow$ \\
\hline Time to $50 \% \mathrm{Ca}^{2+}$ decay & $\downarrow$ & $\downarrow$ \\
\hline \multicolumn{3}{|l|}{ Cardiomyocyte dimension } \\
\hline Cell length & $\uparrow \uparrow$ & $\uparrow$ \\
\hline Cell width & $\uparrow \uparrow$ & $\uparrow$ \\
\hline
\end{tabular}

$\uparrow$, indicates value increase; $\downarrow$, value decrease; $\leftrightarrow$, value remain unchanged; 1 or 2 arrows, indicate size of exercise-induced response
(Adams et al. 2005; Erbs et al. 2010; Hambrecht et al. 2000; Mezzani et al. 2008; Wisloff et al. 2007) trials show improved heart function in similar scenarios of heart disease, we aimed to test the potential value of combining those strategies; first in normal healthy mice. The reasoning for the latter is that exercise training and CaMKII also interact in the heart, as the inotropic effects of exercise training are at least partly modulated by an exercise training-induced increase in CaMKII activity (Kemi et al. 2007). This complicates the combination scenario as CaMKII seems to act as a two edged sword. In fact, CaMKII contributes to decompensate pathologic hypertrophy to heart failure, mainly by its action on the RyR2 to increase SR Ca ${ }^{2+}$ leak (Sag et al. 2009; Ling et al. 2009). Thus, the possibility arises that chronic CaMKII inhibition and exercise training may oppose each other, though it remains to be studied.

As such, this is the first study to introduce the combination of chronic CaMKII inhibition by daily KN-93 injections and aerobic interval exercise training. The main finding was that chronic CaMKII inhibition blunted several 
aspects of the response patterns of cardiomyocyte contractility, and intracellular $\mathrm{Ca}^{2+}$ handling to exercise training, but it did not fully prevent such adaptations. Moreover, CaMKII inhibition also enhanced exercise training-induced improvements on $V \mathrm{O}_{2 \max }$ and aerobic exercise capacity, whereas it did not affect either of them in sedentary mice.

\section{Mechanisms of exercise training-induced adaptation}

The present study provides several mechanistic clues as to the response to exercise training. First, it shows that while CaMKII activation contributes to the cardiac improvements after exercise training (Kemi et al. 2007), other mechanisms must also contribute, as CaMKII inhibition only partly blunted the exercise response. Whether those mechanisms naturally co-exist or occur to compensate for the loss of CaMKII activation remains unknown.

Second, the finding that $V \mathrm{O}_{2 \max }$ and exercise capacity responded more to exercise training in the presence of the chronic CaMKII inhibition compared to the absence thereof indicates that CaMKII also may negatively regulate exercise adaptation in peripheral organs. While this requires further investigation, it is plausible all the while it is ubiquitous and exists in most, if not all, cellular systems (Hudmon and Schulman 2002; Chin 2004).

Third, the opposite effects of exercise training on $V \mathrm{O}_{2 \max }$ and exercise capacity on the one side, and cardiac inotropy and hypertrophy on the other side in the face of CaMKII inhibition highlights that other organs are important in determining $\mathrm{VO}_{2 \max }$ (Bassett and Howley 2000; Coffey and Hawley 2007). In particular, chronic exercise training elicits resistance to muscle fatigue through metabolic responses including mitochondrial biogenesis, increased oxidative capacity, and alterations in gene and protein expression that ultimately leads to phenotype changes that support endurance-type activity (Rose et al. 2007; Benziane et al. 2008; Chin 2004; Coffey and Hawley 2007; Bassett and Howley 2000). The exact mechanism of this rather surprising observation is not known; however, the interaction between CaMKII and calcineurin is a possible candidate. CaMKII modulation of calcineurin signaling is released by CaMKII inhibition. Calcineruin modulates exercise-induced skeletal muscle phenotypes and enhances exercise capacity through increase in mitochondrial oxidative function and energy substrate storage in skeletal muscles (Wang et al. 2011; Jiang et al. 2010). This should be elucidated in future studies.

Cardiac contractile capacity, $\mathrm{Ca}^{2+}$ handling, and CaMKII

Both in vivo and cellular fractional shortening were unaffected by KN-93-induced inhibition of CaMKII in sedentary mice, whereas the expected training-induced increase in both whole-heart and cellular fractional shortening was blunted by the chronic KN-93 treatment. However, chronic CaMKII inhibition did reduce the rate of diastolic cellular relaxation in sedentary mice, which was explained by slower intracellular $\mathrm{Ca}^{2+}$ removal (longer time to $50 \% \mathrm{Ca}^{2+}$ transient decay) and higher systolic $\mathrm{Ca}^{2+}$ levels. Exercise training normalized $\mathrm{Ca}^{2+}$ removal times, and in contrast to fractional shortening, the effect was not blunted by CaMKII inhibition. These results are in accordance with Kemi et al. (2007), who found that acute pre-incubation, with AIP (comparable CaMKII inhibitor) in isolated cardiomyocytes also blunted the exercise training-induced improvements in cellular contractility. Together, these results suggest that CaMKII at least partly modulates the exercise training-induced improvements in cardiac contractility, excitation-contraction coupling, and intracellular $\mathrm{Ca}^{2+}$ handling (Kemi et al. 2007; Stolen et al. 2009). The accumulated evidence also suggests that this modulation occurs via targeting of several loci of excitation-contraction coupling and $\mathrm{Ca}^{2+}$ handling (Stolen et al. 2009). Indeed, fractional shortening is dependent on both SR $\mathrm{Ca}^{2+}$ release and myofilaments $\mathrm{Ca}^{2+}$ sensitivity, where the latter may explain the dissociation between fractional shortening and the intracellular $\mathrm{Ca}^{2+}$ transient amplitude in the present study, as shown directly by others after exercise training (de Waard et al. 2007; Diffee et al. 2001). However, in our experiments we used unloaded myocytes where tension development and basal sarcomere length were not considered.

Current results together with the previous studies (Anderson 2005; Anderson et al. 1998; Couchonnal and Anderson 2008; Erickson and Anderson 2008; Kemi et al. 2007; Khoo et al. 2006; Maier and Bers 2002; Maier et al. 2007; Sag et al. 2009; Vila-Petroff et al. 2007; Zhang et al. 2005) suggest that CaMKII is a versatile kinase that may shift cardiac function into different and also opposite phenotypes. In healthy mice, it appears that a controlled increase in the CaMKII activity increases cardiac contraction (Kemi et al. 2007); that CaMKII inhibition reduces cardiac contraction, and that these effects mainly occur because CaMKII inhibition reduces $\mathrm{SR} \mathrm{Ca}^{2+}$ uptake via SERCA2a. Therefore, it is also possible that the depression of cardiomyocyte contractile parameters by chronic CaMKII inhibition observed here might have progressed to a global dysfunction and a failure if CaMKII inhibition was continued. As such, maintained CaMKII seems to be important for normal cardiomyocyte function in healthy mice. In contrast, the cardiac dysfunction that also has been linked to increased CaMKII activity (Ai et al. 2005; Couchonnal and Anderson 2008; Maier et al. 2007; Zhang and Brown 2004) has mainly been attributed to hypersensitization of the RyR2 to luminal $\mathrm{Ca}^{2+}$ with subsequent 
diastolic SR $\mathrm{Ca}^{2+}$ leak and a shift of $\mathrm{Ca}^{2+}$ out of the cell; a scenario that may lead to contractile dysfunction and increased propensity for arrhythmic events (Sag et al. 2009; Ai et al. 2005; Grimm and Brown 2010; Khoo et al. 2006; Ling et al. 2009; Stolen et al. 2009; Wu et al. 2002), in which CaMKII inhibition or reduction would become particularly beneficial (Kemi et al. 2007; Laurita and Rosenbaum 2008; Li et al. 2006; Vila-Petroff et al. 2007; Yang et al. 2006; Zhang et al. 2005). In a recent modulation study, Hashambhoy et al. (2010) report that inhibition of CaMKII phosphorylation of the L-type $\mathrm{Ca}^{2+}$ channel rather than the RyR2 is more effective in modulating diastolic RyR2 flux. Thus, a pharmacological approach of CaMKII inhibition in the heart should also target the L-type $\mathrm{Ca}^{2+}$ channel in order to prevent or treat cardiac dysfunction and disease. Whether this will be feasible remains to be investigated. KN-93 inhibits CaMKII by competing for the calmodulin binding site, and has been widely used to implicate roles of CaMKII in $\mathrm{Ca}^{2+}$ handling (Sumi et al. 1991). KN-93 is not heart-specific and is known to have other actions than CaMKII inhibition (Anderson et al. 1998; Gao et al. 2006). Previous studies have observed that KN-93 might inhibit L-type $\mathrm{Ca}^{2+}$ current independent of CaMKII (Anderson et al. 1998; Gao et al. 2006). This negative effect of KN-93 on intracellular $\mathrm{Ca}^{2+}$ levels are balanced by inhibition of voltage-dependent potassium currents which enhance $\mathrm{Ca}^{2+}$ entry via L-type $\mathrm{Ca}^{2+}$ channel (Anderson et al. 1998; Rezazadeh et al. 2006; Ledoux et al. 1999). The lack of organ specificity of KN-93 is a limitation of this study, and interpretations should be considered with caution. We did, however, control for non-cardiac side effects of chronic KN-93 injections by the pathological examinations of the vital organs after euthanasia in mice.

\section{Physiological hypertrophy}

Echocardiography measurements observed a trend for decreased LV mass in sedentary KN-93 treated mice, which was normalized by exercise-induced hypertrophy, and cardiomyocyte length and width increased significantly less in KN-93-treated mice compared to sham-treated mice. These results are somewhat similar to the observations of Zhang et al. (2005), with myocardial infarction as the physiological stressor, who reported that cardiomyocyte transverse cross-sectional area and heart weight were comparably smaller after genetic inhibition of CaMKII than in control cardiomyocytes. Furthermore, Ramirez et al. (1997) reported that pre-treatment with KN-93 blocked hypertrophic responses to the hypertrophy developed by pressure overload or endothelin-1 (Zhang et al. 2004; Zhu et al. 2000). Our observation suggests that CaMKII may also modulate cardiomyocyte growth in response to exercise training (physiological hypertrophy) and not only in response to the pathologic conditions.

\section{Conclusion}

This study indicates the importance of maintaining normal CaMKII activity in cardiomyocytes of healthy individuals, also because it positively modulates inotropic/lusitropic responses to exercise training. However, targeting CaMKII by selective inhibitors has recently been suggested to correct cardiac dysfunction and prevent decompensation and progression of heart disease; a clinical scenario that also is targeted by exercise training. This study indicates that a combination strategy of CaMKII inhibition and exercise training may be feasible for the purpose of attenuating heart disease, although this does present a complex scenario that may also reduce some of the beneficial effects of exercise training, especially if CaMKII inhibitors cannot be closely tuned into localized subcellular targets that mainly cause the cardiac dysfunction.

\section{Limitations}

The small molecule inhibitor KN-93 has potential nonspecific effects other than CaMKII inhibition which were not controlled for; this is a limitation of the present study. The pathological examinations were done to rule out effects on the results from any of the other vital organs due to KN-93 or DMSO injections.

Acknowledgments We thank Trine Skoglund for excellent laboratory assistance. The study was supported by grants from the K.G. Jebsen Foundation; the Blix Foundation for the Promotion of Medical Science (GK), and the Norwegian Research Council Funding for Outstanding Young Investigators (UW), and the British Heart Foundation (OJK).

\section{Conflict of interest None.}

Open Access This article is distributed under the terms of the Creative Commons Attribution Noncommercial License which permits any noncommercial use, distribution, and reproduction in any medium, provided the original author(s) and source are credited.

\section{References}

Adams V, Linke A, Krankel N, Erbs S, Gielen S, Mobius-Winkler S, Gummert JF, Mohr FW, Schuler G, Hambrecht R (2005) Impact of regular physical activity on the $\mathrm{NAD}(\mathrm{P}) \mathrm{H}$ oxidase and angiotensin receptor system in patients with coronary artery disease. Circulation 111(5):555-562. doi:10.1161/01.CIR.0000154560.88933.7E

Ai X, Curran JW, Shannon TR, Bers DM, Pogwizd SM (2005) Ca2+/ calmodulin-dependent protein kinase modulates cardiac ryanodine receptor phosphorylation and sarcoplasmic reticulum $\mathrm{Ca} 2+$ 
leak in heart failure. Circ Res 97(12):1314-1322. doi:10.1161/ 01.RES.0000194329.41863.89

Anderson ME (2005) Calmodulin kinase signaling in heart: an intriguing candidate target for therapy of myocardial dysfunction and arrhythmias. Pharmacol Ther 106(1):39-55. doi:10.1016/ j.pharmthera.2004.11.002

Anderson ME, Braun AP, Wu Y, Lu T, Schulman H, Sung RJ (1998) $\mathrm{KN}-93$, an inhibitor of multifunctional $\mathrm{Ca}++/$ calmodulindependent protein kinase, decreases early after depolarizations in rabbit heart. J Pharmacol Exp Ther 287(3):996-1006

Bassett DR Jr, Howley ET (2000) Limiting factors for maximum oxygen uptake and determinants of endurance performance. Med Sci Sports Exerc 32(1):70-84

Benziane B, Burton TJ, Scanlan B, Galuska D, Canny BJ, Chibalin AV, Zierath JR, Stepto NK (2008) Divergent cell signaling after short-term intensified endurance training in human skeletal muscle. Am J Physiol Endocrinol Metab 295(6):E1427-E1438. doi:10.1152/ajpendo.90428.2008

Chin ER (2004) The role of calcium and calcium/calmodulindependent kinases in skeletal muscle plasticity and mitochondrial biogenesis. Proc Nutr Soc 63(2):279-286. pii:10.1079/ PNS2004335S0029665104000370

Coffey VG, Hawley JA (2007) The molecular bases of training adaptation. Sports Med 37(9):737-763

Couchonnal LF, Anderson ME (2008) The role of calmodulin kinase II in myocardial physiology and disease. Physiology 23:151-159. doi:10.1152/physiol.00043.2007

de Waard MC, van der Velden J, Bito V, Ozdemir S, Biesmans L, Boontje NM, Dekkers DHW, Schoonderwoerd K, Schuurbiers $\mathrm{HCH}$, de Crom R, Stienen GJM, Sipido KR, Lamers JMJ, Duncker DJ (2007) Early exercise training normalizes myofilament function and attenuates left ventricular pump dysfunction in mice with a large myocardial infarction. Circ Res 100(7): 1079-1088. doi:10.1161/01.Res.0000262655.16373.37

Diffee GM, Seversen EA, Titus MM (2001) Exercise training increases the $\mathrm{Ca} 2+$ sensitivity of tension in rat cardiac myocytes. J Appl Physiol 91:309-315

Erbs S, Hollriegel R, Linke A, Beck EB, Adams V, Gielen S, MobiusWinkler S, Sandri M, Krankel N, Hambrecht R, Schuler G (2010) Exercise training in patients with advanced chronic heart failure (NYHA IIIb) promotes restoration of peripheral vasomotor function, induction of endogenous regeneration, and improvement of left ventricular function. Circ Heart Fail 3(4):486-494. doi:10.1161/CIRCHEARTFAILURE.109.868992

Erickson JR, Anderson ME (2008) CaMKII and its role in cardiac arrhythmia. J Cardiovasc Electrophysiol 19(12):1332-1336. doi: 10.1111/j.1540-8167.2008.01295.x

Gao L, Blair LAC, Marshall J (2006) CaMKII-independent effects of KN93 and its inactive analog KN92: reversible inhibition of L-type calcium channels. Biochem Biophys Res Commun 345:1606-1610

Grimm M, Brown JH (2010) Beta-adrenergic receptor signaling in the heart: role of CaMKII. J Mol Cell Cardiol 48(2):322-330. doi: 10.1016/j.yjmcc.2009.10.016

Guatimosim S, Sobie EA, Cruz JDS, Martin LA, Lederer WJ (2001) Molecular identification of a TTX-sensitive Ca2+ current. Am J Physiol Cell Physiol 280:1327-1339

Hambrecht R, Wolf A, Gielen S, Linke A, Hofer J, Erbs S, Schoene N, Schuler G (2000) Effect of exercise on coronary endothelial function in patients with coronary artery disease. N Engl J Med 342(7):454-460. doi:10.1056/NEJM200002173420702

Hashambhoy YL, Greenstein JL, Winslow RL (2010) Role of CaMKII in RyR leak, EC coupling and action potential duration: a computational model. J Mol Cell Cardiol. doi:10.1016/ j.yjmcc.2010.1007.1011
Hoydal MA, Wisloff U, Kemi OJ, Ellingsen O (2007) Running speed and maximal oxygen uptake in rats and mice: practical implications for exercise training. Eur J Cardiovasc Prev Rehabil 14(6):753-760. doi:10.1097/HJR.0b013e3281eacef1

Hudmon A, Schulman H (2002) Structure-function of the multifunctional $\mathrm{Ca} 2+/$ calmodulin-dependent protein kinase II. Biochem J 364:593-611

Jiang LQ, Garcia-Roves PM, de Castro Barbosa T, Zierath JR (2010) Constitutively active calcineurin in skeletal muscle increases endurance performance and mitochondrial respiratory capacity. Am J Physiol Endocrinol Metab 298(1):E8-E16. doi:10.1152/ ajpendo.00403.2009

Kemi OJ, Loennechen JP, Wisloff U, Ellingsen O (2002) Intensitycontrolled treadmill running in mice: cardiac and skeletal muscle hypertrophy. J Appl Physiol 93(4):1301-1309. doi:10.1152/ japplphysiol.00231.2002

Kemi OJ, Haram PM, Loennechen JP, Osnes JB, Skomedal T, Wisloff U, Ellingsen O (2005) Moderate vs. high exercise intensity: differential effects on aerobic fitness, cardiomyocyte contractility, and endothelial function. Cardiovasc Res 67 (1):161-172. doi:10.1016/j.cardiores.2005.03.010

Kemi OJ, Ellingsen O, Ceci M, Grimaldi S, Smith GL, Condorelli G, Wisloff U (2007) Aerobic interval training enhances cardiomyocyte contractility and $\mathrm{Ca} 2+$ cycling by phosphorylation of CaMKII and Thr-17 of phospholamban. J Mol Cell Cardiol 43(3):354-361. doi:10.1016/j.yjmcc.2007.06.013

Khoo MS, Li J, Singh MV, Yang Y, Kannankeril P, Wu Y, Grueter CE, Guan X, Oddis CV, Zhang R, Mendes L, Ni G, Madu EC, Yang J, Bass M, Gomez RJ, Wadzinski BE, Olson EN, Colbran RJ, Anderson ME (2006) Death, cardiac dysfunction, and arrhythmias are increased by calmodulin kinase II in calcineurin cardiomyopathy. Circulation 114(13):1352-1359. doi:10.1161/ CIRCULATIONAHA.106.644583

Laurita KR, Rosenbaum DS (2008) Mechanisms and potential therapeutic targets for ventricular arrhythmias associated with impaired cardiac calcium cycling. J Mol Cell Cardiol 44(1): 31-43. doi:10.1016/j.yjmcc.2007.10.012

Ledoux J, Chartier D, Leblanc N (1999) Inhibitors of calmodulindependent protein kinase are nonspecific blockers of voltagedependent $\mathrm{K}+$ channels in vascular myocytes. J Pharmacol Exp Ther 290(3):1165-1174

Li J, Marionneau C, Zhang R, Shah V, Hell JW, Nerbonne JM, Anderson ME (2006) Calmodulin kinase II inhibition shortens action potential duration by upregulation of $\mathrm{K}+$ currents. Circ Res 99(10):1092-1099. doi:10.1161/01.RES.0000249369.71709.5c

Ling H, Zhang T, Pereira L, Means CK, Cheng H, Gu Y, Dalton ND, Peteron KL, Chen J, Bers D, Brown JH (2009) Requirement for $\mathrm{Ca} 2+/$ calmodulin-dependent kinase II in the transition from pressure overload-induced cardiac hypertrophy to heart failure in mice. J Clin Invest 119:1230-1240

MacDonnell SM, Weisser-Thomas J, Kubo H, Hanscome M, Liu Q, Jaleel N, Berretta R, Chen X, Brown JH, Sabri AK, Molkentin JD, Houser SR (2009) CaMKII negatively regulates calcineurinNFAT signaling in cardiac myocytes. Circ Res 105(4):316-325. doi:10.1161/CIRCRESAHA.109.194035

Maier LS, Bers DM (2002) Calcium, calmodulin, and calciumcalmodulin kinase II: heartbeat to heartbeat and beyond. J Mol Cell Cardiol 34(8):919-939. pii:S0022282802920389

Maier LS, Bers DM (2007) Role of Ca2+/calmodulin-dependent protein kinase (CaMK) in excitation-contraction coupling in the heart. Cardiovasc Res 73:631-640

Maier LS, Bers DM, Brown JH (2007) Calmodulin and $\mathrm{Ca} 2+/$ calmodulin kinases in the heart-physiology and pathophysiology. Cardiovasc Res 73(4):629-630. doi:10.1016/j.cardiores. 2007.01.005 
Mezzani A, Corra U, Giannuzzi P (2008) Central adaptations to exercise training in patients with chronic heart failure. Heart Fail Rev 13(1):13-20. doi:10.1007/s10741-007-9053-y

Mitra R, Morad M (1981) A uniform enzymatic method for dissociation of myocytes from hearts and stomachs of vertebrates. Pflugers Arch 391:85-100

Ramirez MT, Zhao X, Schulman H, Brown JH (1997) The nuclear deltaB isoform of $\mathrm{Ca} 2+/$ Calmodulin-dependent protein kinase II regulated atrial natriuretic factor gene expression in ventricular myocytes. J Biol Chem 272:31203-31208

Rezazadeh S, Claydon TW, Fedida D (2006) KN-93 (2-[N-(2-hydroxyethyl)]- $N$-(4-methoxybenzenesulfonyl)]amino- $N$-(4-chlorocinn amyl)- $N$-methylbenzylamine), a calcium/calmodulin-dependent protein kinase II inhibitor, is a direct extracellular blocker of voltage-gated potassium channels. J Pharmacol Exp Ther 317(1):292-299. doi:10.1124/jpet.105.097618

Rose AJ, Frosig C, Kiens B, Wojtaszewski JF, Richter EA (2007) Effect of endurance exercise training on $\mathrm{Ca} 2+$ calmodulindependent protein kinase II expression and signalling in skeletal muscle of humans. J Physiol 583(Pt 2):785-795. doi:10.1113/ jphysiol.2007.138529

Sag CM, Wadsack DP, Khabbazzadeh S, Abesser M, Grefe C, Neumann K, Opiela MK, Backs J, Olson EN, Brown JH, Neef S, Maier SK, Maier LS (2009) Calcium/calmodulin-dependent protein kinase II contributes to cardiac arrhythmogenesis in heart failure. Circ Heart Fail 2(6):664-675. doi:10.1161/ CIRCHEARTFAILURE.109.865279

Stolen TO, Hoydal MA, Kemi OJ, Catalucci D, Ceci M, Aasum E, Larsen T, Rolim N, Condorelli G, Smith GL, Wisloff U (2009) Interval training normalizes cardiomyocyte function, diastolic $\mathrm{Ca} 2+$ control, and $\mathrm{SR} \mathrm{Ca} 2+$ release synchronicity in a mouse model of diabetic cardiomyopathy. Circ Res 105(6):527-536. doi:10.1161/CIRCRESAHA.109.199810

Sumi MKK, Ishikawa T, Ishii A, Hagiwara M, Nagatsu T, Hidaka H (1991) The newly synthesized selective $\mathrm{Ca} 2+/$ calmodulin dependent protein kinase II inhibitor $\mathrm{KN}-93$ reduces dopamine contents in $\mathrm{PC} 12 \mathrm{~h}$ cells. Biochem Biophys Res Commun 181:968-975

Taylor CR, Maloiy GM, Weibel ER, Langman VA, Kamau JM, Seeherman HJ, Heglund NC (1981) Design of the mammalian respiratory system. III Scaling maximum aerobic capacity to body mass: wild and domestic mammals. Respir Physiol 44 (1):25-37

Tjonna AE, Lee SJ, Rognmo O, Stolen TO, Bye A, Haram PM, Loennechen JP, Al-Share QY, Skogvoll E, Slordahl SA, Kemi OJ, Najjar SM, Wisloff U (2008) Aerobic interval training versus continuous moderate exercise as a treatment for the metabolic syndrome: a pilot study. Circulation 118(4):346-354. doi: 10.1161/CIRCULATIONAHA.108.772822

van Oort RJ, McCauley MD, Dixit SS, Pereira L, Yang Y, Respress JL, Wang Q, De Almeida AC, Skapura DG, Anderson ME, Bers DM, Wehrens XH (2010) Ryanodine receptor phosphorylation by calcium/calmodulin-dependent protein kinase II promotes life-threatening ventricular arrhythmias in mice with heart failure. Circulation 122(25):2669-2679. doi: 10.1161/CIRCULATIONAHA.110.982298

Vila-Petroff M, Salas MA, Said M, Valverde CA, Sapia L, Portiansky E, Hajjar RJ, Kranias EG, Mundina-Weilenmann C, Mattiazzi A (2007) CaMKII inhibition protects against necrosis and apoptosis in irreversible ischemia-reperfusion injury. Cardiovasc Res 73(4):689-698. doi:10.1016/j.cardiores.2006.12.003

Wang JX, Jiao JQ, Li Q, Long B, Wang K, Liu JP, Li YR, Li PF (2011) miR-499 regulates mitochondrial dynamics by targeting calcineurin and dynamin-related protein-1. Nat Med 17(1): 71-78. doi: $10.1038 / \mathrm{nm} .2282$

Wisloff U, Helgerud J, Kemi OJ, Ellingsen O (2001) Intensitycontrolled treadmill running in rats: $\mathrm{VO}(2$ max $)$ and cardiac hypertrophy. Am J Physiol Heart Circ Physiol 280(3):H1301H1310

Wisloff U, Loennechen JP, Currie S, Smith GL, Ellingsen O (2002) Aerobic exercise reduces cardiomyocyte hypertrophy and increases contractility, $\mathrm{Ca} 2+$ sensitivity and SERCA-2 in rat after myocardial infarction. Cardiovasc Res 54(1):162-174. pii: S000863630100565X

Wisloff U, Stoylen A, Loennechen JP, Bruvold M, Rognmo O, Haram PM, Tjonna AE, Helgerud J, Slordahl SA, Lee SJ, Videm V, Bye A, Smith GL, Najjar SM, Ellingsen O, Skjaerpe T (2007) Superior cardiovascular effect of aerobic interval training versus moderate continuous training in heart failure patients: a randomized study. Circulation 115(24):3086-3094. doi:10.1161/ CIRCULATIONAHA.106.675041

Wu Y, Temple J, Zhang R, Dzhura I, Zhang W, Trimble R, Roden DM, Passier R, Olson EN, Colbran RJ, Anderson ME (2002) Calmodulin kinase II and arrhythmias in a mouse model of cardiac hypertrophy. Circulation 106(10):1288-1293

Yang Y, Zhu WZ, Joiner ML, Zhang R, Oddis CV, Hou Y, Yang J, Price EE, Gleaves L, Eren M, Ni G, Vaughan DE, Xiao RP, Anderson ME (2006) Calmodulin kinase II inhibition protects against myocardial cell apoptosis in vivo. Am J Physiol Heart Circ Physiol 291(6):H3065-H3075. doi:10.1152/ajpheart.00353.2006

Zhang T, Brown JH (2004) Role of Ca2+/calmodulin-dependent protein kinase II in cardiac hypertrophy and heart failure. Cardiovasc Res 63(3):476-486. doi:10.1016/j.cardiores.2004.04.026

Zhang T, Miyamoto S, Brown JH (2004) Cardiomyocyte calcium and calcium/calmodulin-dependent protein kinase II: friends or foes? Recent Prog Horm Res 59:141-168

Zhang R, Khoo MS, Wu Y, Yang Y, Grueter CE, Ni G, Price EE Jr, Thiel W, Guatimosim S, Song LS, Madu EC, Shah AN, Vishnivetskaya TA, Atkinson JB, Gurevich VV, Salama G, Lederer WJ, Colbran RJ, Anderson ME (2005) Calmodulin kinase II inhibition protects against structural heart disease. Nat Med 11(4):409-417. doi:10.1038/nm1215

Zhu WZ, Zou Y, Shiojima I, Kudoh S, Aikawa R, Hayashi D, Mizukami M, Toko H, Shibasaki F, Yazaki Y, Nagai R, Komuro I (2000) Ca2+/Calmodulin-dependent Kinase II and Calcineurin play critical roles in endothelin-1-induced cardiomyocyte hypertrophy. J Biol Chem 275(19):15239-15245 